\title{
Influence of Equal Channel Angular Pressing on Tribological Properties of Low Carbon Steel (Fe-0,09C-0,64Si-,26Mn)
}

\author{
P. G. Mordovskoi, S. P. Yakovleva, S. N. Maharova \\ Department of Material Science, The V.P. Larionov Institute of Physical and Technical Problems of the North SB \\ RAS, Yakutsk, Russia \\ Email: mordov@yandex.ru
}

Received 6 November 2014; revised 9 December 2014; accepted 22 December 2014

Copyright (C) 2015 by authors and Scientific Research Publishing Inc.

This work is licensed under the Creative Commons Attribution International License (CC BY). http://creativecommons.org/licenses/by/4.0/

(c) (i) Open Access

\begin{abstract}
This paper presents the results of equal channel angular pressing (ECAP) and subsequent heat treatment (HT) as a method to improve the wear resistance of metallic materials in friction sliding. The effect of ECAP and HT on the microstructure and mechanical properties of low carbon steel is investigated in this work. The mechanisms of wear resistance of steel with ultrafine and nanostructures produced by equal-channel angular pressing is analyzed. The results show that ECAP at room temperature and annealing at $350^{\circ} \mathrm{C}$ and $450^{\circ} \mathrm{C}$ can be used as a technology of reducing wear in friction sliding.
\end{abstract}

\section{Keywords}

Low Carbon Steel, Equal Channel Angular Pressing, Ultrafine and Nano-Structures, Heat Treatment, Wear

\section{Introduction}

Severe plastic deformation (SPD) by equal channel angular pressing (ECAP) significantly affects the structure and properties of the material [1]. In ECAP conditions, the billet is pressed through a steel matrix having two channels with the same cross section, intersecting at an angle $\Phi$, which is usually equal to $90^{\circ}$. Specimen is mechanically processed to fit tightly to the wall of the channel. Most of the scientific studies on the influence of ECAP describe the change in the structure and mechanical properties of non-ferrous metals and their alloys [2]-[4]. Currently, the practice of ECAP industrial use requires more complete information about the behavior of the material in tribological conditions. 
Objective is to study the tribological properties of low carbon steel with ultra and nanostructures formed by ECAP and low-temperature annealing.

\section{Experimental}

\subsection{Materials}

The studies were conducted on widely used in Russia steel 09G2S. Chemical composition of 09G2S is: Fe-0, 09C-0,64Si-1,26Mn-0,007P-0,003S-0,08Cr-0,1Ni-0,02Al-0,14Cu-0,002V-0,01Nb-0,013Ti. Samples of 09G2S with the diameter of $20 \mathrm{~mm}$ and the length of $100 \mathrm{~mm}$ were pressed for ECAP at $20^{\circ} \mathrm{C}$. ECAP was held by two press cycles on the route $\mathrm{Bc}\left(90^{\circ}\right.$ turn after each compression) with the angle of intersection of channels $\Phi=90^{\circ}$; after ECAP samples were subjected to heat treatment (HT): short-term low temperature annealing at $350^{\circ} \mathrm{C}$ and $450^{\circ} \mathrm{C}$ delayed for 1 hour [5]. After ECAP and HT, we prepared samples for tribological tests in the form of a bar with dimensions: $5 \times 10 \times 5 \mathrm{~mm}$ with roughness Ra 2 .

\subsection{Experimental Methods}

Microstructure studies were conducted using a scanning electron microscope JEOL JSM-6480LV. Tribological tests were performed on a friction machine with the contact area $5 \times 5 \mathrm{~mm}$. Tests of dry sliding friction was carried out on the steel plate with the hardness of 50 - 52 HRC, friction path—560 m, load—150, 225, 300 and 375 N [6].

\section{Results and Discussion}

\subsection{Microstructure}

The microstructure of the starting material was ferritic-pearlitic, ferrite grain size ranges between $4.35 \mu \mathrm{m}$ (the middle diameter $-10 \mu \mathrm{m}$ ). The previous studies [5] of steel 09G2S after ECAP showed that its microstructure consists of distributions in the deformed ferritic matrix carbides with diameter of $\sim 300-500 \mathrm{~nm}$. The average size of ferritic areas free of carbide phase is about $5 \mu \mathrm{m}$, which is more than 2 times lower than the average ferrite grain size of the original.

Figure 1 shows the microstructure of the steel after ECAP and HT: the average size of ferritic sites decreases, the process of carbides dispersion continues, accompanied by their spheroidizing and dispersal. In lamellar pearlite groups during the deformation there can be observed change distances between plates; in the ferrite plates there is formation of cellular structure, elongated along the axis of sliding as a secondary slip system, plates of cement carbide gradually get thinner and fragmented.

\subsection{Mechanical Properties}

Mechanical properties of tensile specimens are shown in Table 1. As can be seen from Table 1, ECAP caused an almost threefold increase in the yield strength $\sigma_{\mathrm{T}}$ and tensile strength $\sigma_{\mathrm{B}}$ compared to initial state. Convergence of these indicators is quite common for steel in high-strength state. The sharp increase in strength is due to intensive dispersion. The highest strength values to samples processed in the following modes: ECAP at $20^{\circ} \mathrm{C}$ and heating to $350^{\circ} \mathrm{C}$, ECAP at $20^{\circ} \mathrm{C}$ without $\mathrm{HT}$ and ECAP at $350^{\circ} \mathrm{C}$ without $\mathrm{HT}$, respectively.

\subsection{Tribological Properties}

Tribological properties of ferritic-pearlitic steel is determined by a complex of physical and mechanical charac-

Table 1. Mechanical properties of steel 09G2S after various types of treatment.

\begin{tabular}{ccc} 
Processing Options & \multicolumn{1}{c}{ Mechanical properties } & $\sigma_{\mathrm{B}}, \mathrm{MPa}, \%$ \\
Initial state & $\sigma_{\mathrm{T}}, \mathrm{MPa}$ & 370 \\
$\mathrm{ECAP}$ at $20^{\circ} \mathrm{C}$, without $\mathrm{HT}$ & 930 & 1300 \\
$\mathrm{ECAP}$ at $20^{\circ} \mathrm{C}$, annealing at $350^{\circ} \mathrm{C}$ & 985 & 3 \\
$\mathrm{ECAP}$ at $20^{\circ} \mathrm{C}$, annealing at $450^{\circ} \mathrm{C}$ & 850 & 1400 \\
\hline
\end{tabular}



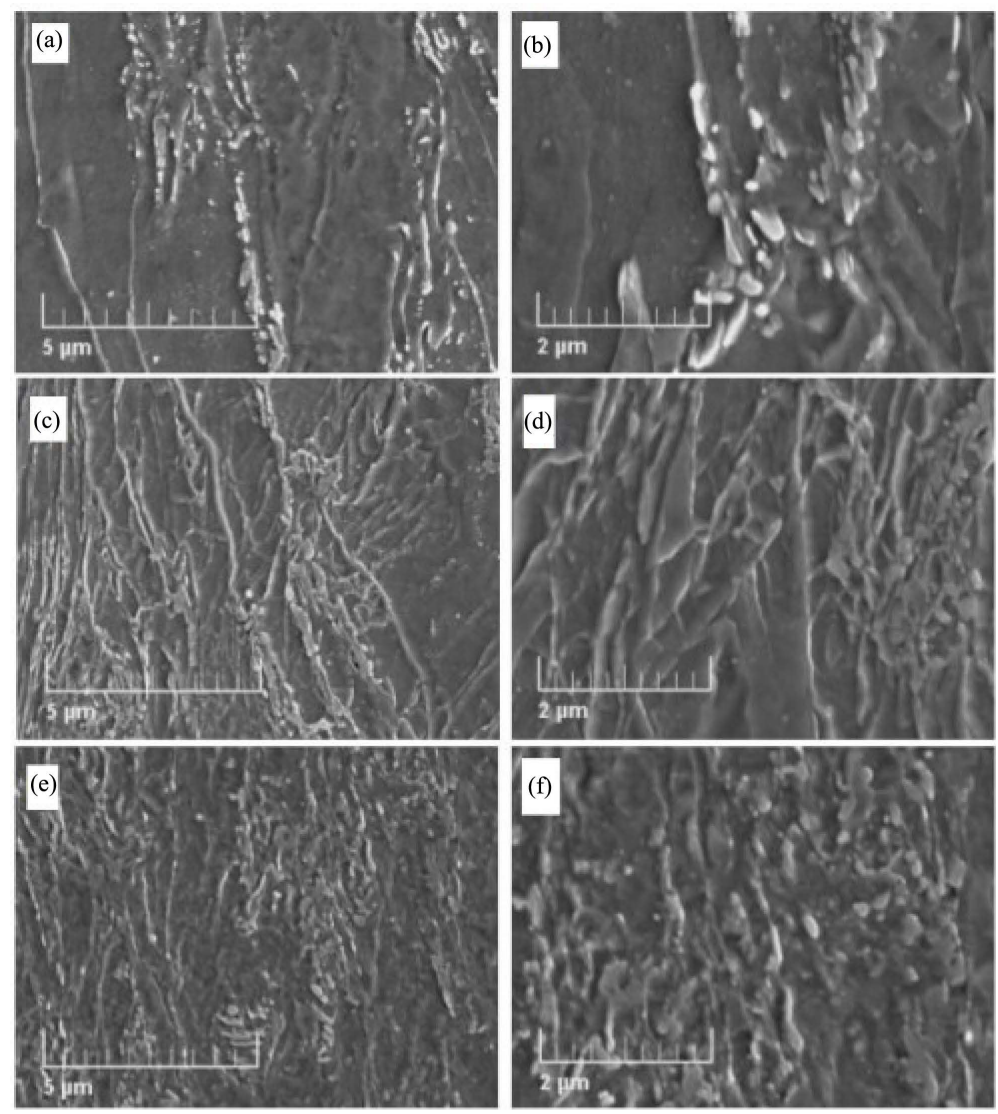

Figure 1. Microstructure after cold ECAP with increasing of (a) $\times 10,000$; (b)

$\times 20,000$; after cold ECAP and annealing at $350^{\circ} \mathrm{C}$; (c) $\times 10,000$; (d) $\times 20,000$; after cold ECAP and annealing at $450^{\circ} \mathrm{C}$; (e) $\times 10,000$; (f) $\times 20,000$.

teristics depending on the number and dispersion of structurally free ferrite, the size and shape of the carbide particles, the deformation behavior, resistance emergence of micro cracks. To improve wear resistance, we need to apply chemical, thermal and mechanical processing, which cause growth of hardness, optimal distribution of dispersed particles of the carbide phase, microalloying, etc.

Table 2 shows the results of tribological tests under dry sliding with different values of the normal load. Wear samples at initial state and after ECAP at 150 and $225 \mathrm{~N}$ of load is low. Load growth up to $300 \mathrm{~N}$ leads to a significant increase in raw material deterioration due to the transition to adhesive seizure. Wear on the air was 360 mg; after ECAP without annealing it was $140 \mathrm{mg}$ and after ECAP with annealing at $350^{\circ} \mathrm{C}$ and $450^{\circ} \mathrm{C}-6$ and 5 $\mathrm{mg}$, respectively. More wear resistance of the samples, processed by ECAP is due to the increase in hardness and strength, as well as structural changes (grain refinement, the increasing number of large-grain boundaries, etc.). After ECAP and subsequent annealing, additional reinforcement of submicrometer ferrite matrix takes place due to the appearance and more uniform distribution of the nanoparticles of the carbide phase and decrease of tension deformation in the samples.

At a load of $375 \mathrm{~N}$ massive deterioration in air samples is reduced as a consequence of changes in the regime of friction, which increases the ability of a material to resist cracking and the formation of wear particles, but in the sample after ECAP and annealing at $450^{\circ} \mathrm{C}$ there was a single increase in depreciation to the value of $260 \mathrm{mg}$, which corresponds to changing the nature of friction from microcutting to adhesive seizure. During the tests in the areas of actual contact under the load, softer pattern is strengthened by increase of density of dislocations and the formation of secondary fragmented structure of the surface layer. Further, the plastic deformation causes mutual reinforcement of the friction pair materials and change in roughness of contact surfaces. This continues until the friction operating voltages decreasing with the growth of real contact area, will not be comparable to the yield strength of the materials of the friction pair. At this point, there comes a stage of steady deterioration, characterized by the equilibrium roughness and stabilization structures: there takes place dynamic equilibrium 
Table 2. Mass wear in dry sliding friction.

\begin{tabular}{ccccc}
\hline & \multicolumn{3}{c}{ Mass loss of samples, $\Delta \mathrm{m}, \mathrm{mg}$} \\
\cline { 2 - 5 } The test load, $\mathbf{N}$ & Initial state & ECAP & ECAP $\mathrm{HT}$ at $350^{\circ} \mathrm{C}$ & ECAP $\mathrm{HT}$ at $450^{\circ} \mathrm{C}$ \\
\hline 150 & 7 & 7 & 10 & 6 \\
225 & 8 & 5 & 6 & 5 \\
300 & 360 & 140 & 20 & 3 \\
375 & 260 & 2 & 2 & 2 \\
\hline
\end{tabular}

between the formation and destruction of secondary structures of mechanic and chemical origin, i.e. uneven over time cyclic wear of friction surface can be observed due to the specifics of elastic deformation of the surface layers of bodies.

Better wear resistance was shown by the steel, treated under the regime of ECAP and HT. High wear resistance steel with UFG and nanostructure formed by ECAP HT was due to the peculiarities of volumetrically strained material tribological destruction. After ECAP can be observed texturing of ferrite grains along the axis of the billet, which coincides with the axis of the channel matrix, which should affect the structure of the surface formed by friction, depending on the direction of tribological pair. Under the tribological treatment of the deformed steel in the surface layer, the following processes occur: the destruction (fragmentation) of ferrite grains, texturing of ferritic bands and redistribution of carbides along the slip line; there can also be observed greater effect of such things as grain-boundary sliding and rotation of large-grains in the UFG and nanostructured materials. Effect of tribological pair heating partially causes recrystallization of grains in the surface layer of the material. Smaller grain size should provide more uniform removal of wear particles from the friction surface, compared with the initial coarse-grained material. Further movement of the wear particles along the friction surface should cause less destruction of the friction surface, i.e. effect of abrasion wear is reduced as well as "gouging” the friction surface by wear particles.

\section{Conclusion}

The results obtained show that during the low-temperature annealing at $350^{\circ} \mathrm{C}$ and $450^{\circ} \mathrm{C}$, ECAP can be used as a technology to reduce wear in friction sliding unless the critical load is not exceeded. Then the load is greater than the tensile strength of the material.

\section{References}

[1] Valiev, R.Z. and Alexandrov, I.V. (2000) Nanostructured Materials Produced by Severe Plastic Deformation. Logos.

[2] Zha, M., Li, Y.-J., Mathiesen, R., Bjørge, R. and Roven, H.J. (2014) Microstructure, Hardness Evolution and Thermal Stability of Binary Al-7Mg Alloy Processed by ECAP with Intermediate Annealing. Transactions of Nonferrous Metals Society of China, 24, 2301-2306.

[3] Yu, X., Li, Y.L. and Li, L. (2014) Effect of Grain Refinement on Fracture Toughness and Fracture Mechanism in AZ31 Magnesium Alloy. Procedia Materials Science, 3, 1780-1785. http://dx.doi.org/10.1016/j.mspro.2014.06.287

[4] Shaeri, M.H., Salehi, M.T., Seyyedein, S.H., Abutalebi, M.R. and Park, J.K. (2014) Microstructure and Mechanical Properties of Al-7075 Alloy Processed by Equal Channel Angular Pressing Combined with Aging Treatment. Materials \& Design, 57, 250-257. http://dx.doi.org/10.1016/j.matdes.2014.01.008

[5] Yakovleva, S.P., Maharova, S.N. and Borisova, M.Z. (2009) The Formation of Nanoscale Structural Elements in Steel 09G2S at Low Temperature Annealing after Severe Plastic Deformation. Collection of Articles of the III International Conference "Deformation and Fracture of Materials and Nanomaterials", Moscow, 2004, Vol. 1, 256-257.

[6] Yakovleva, S.P., Maharova, S.N., Mordovskoy, P.G., Borisova, M.Z. and Vinokurov G.G. (2011) Wear Resistance and Friction Surface of Alloy Steel with Different Grain Size. Metallurgy Engineering, 4, 26-29. 
Scientific Research Publishing (SCIRP) is one of the largest Open Access journal publishers. It is currently publishing more than 200 open access, online, peer-reviewed journals covering a wide range of academic disciplines. SCIRP serves the worldwide academic communities and contributes to the progress and application of science with its publication.

Other selected journals from SCIRP are listed as below. Submit your manuscript to us via either submit@scirp.org or Online Submission Portal.
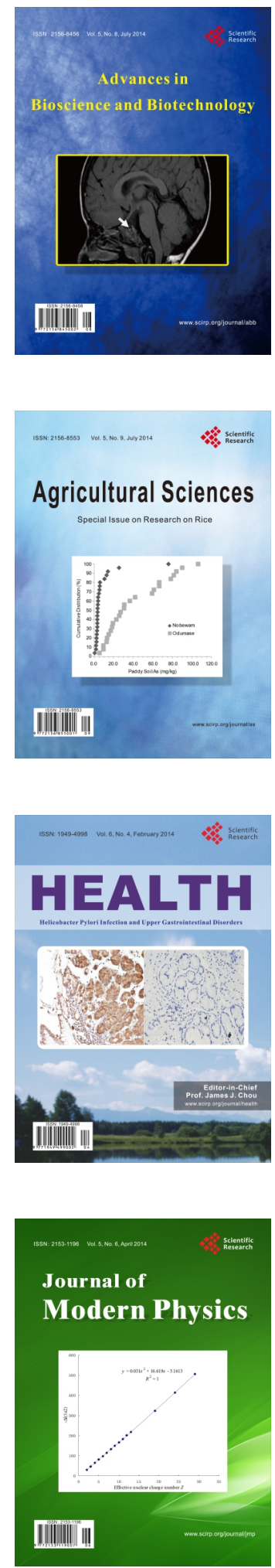
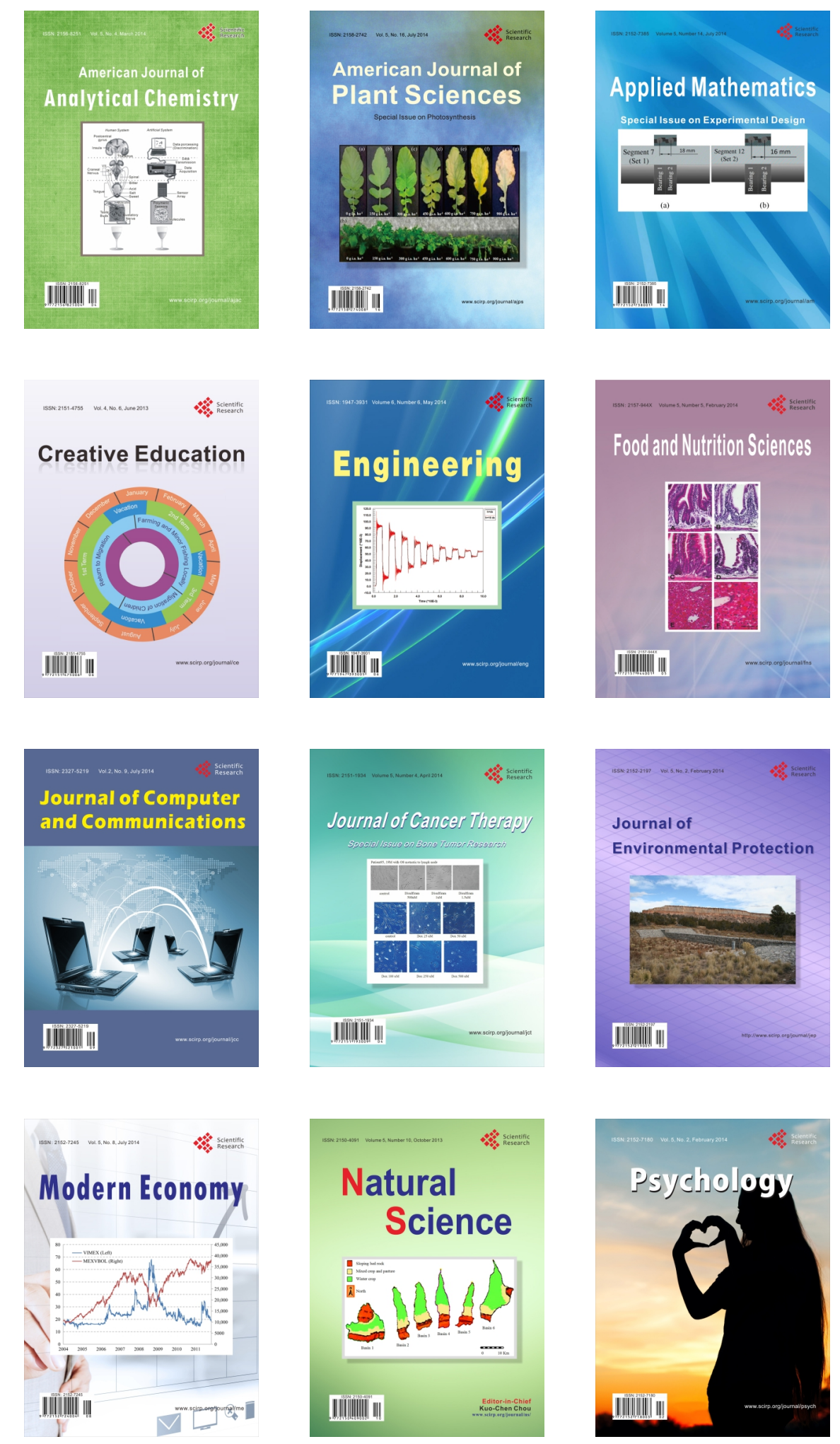